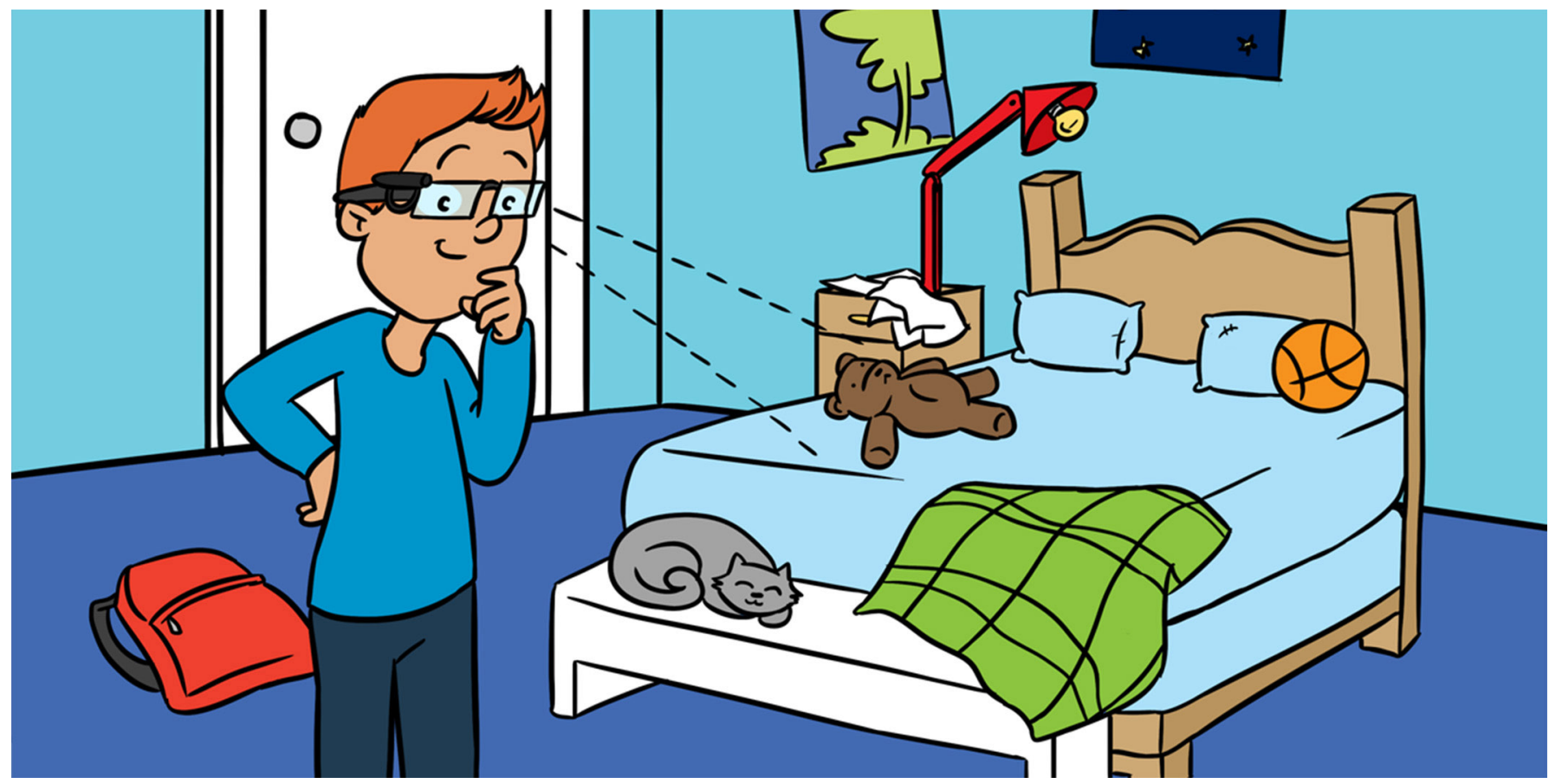

\title{
EYE SPY: WHY WE NEED TO MOVE OUR EYES TO GATHER INFORMATION ABOUT THE WORLD
}

\section{Jessica Madrid and Michael C. Hout*}

Psychology Department, New Mexico State University, Las Cruces, NM, United States

\section{YOUNG REVIEWER:}

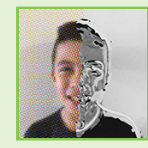

GONI

AGE: 10
You probably think about what you see all the time. But have you ever stopped to think about how you see? In order to see objects in the environment, the brain first needs information from the eyes. Once this information is available, the brain can use it to create a mental picture of the world. For the most part, we feel as if we see the details of our surroundings very clearly, and our visual experience appears to be smooth and continuous. However, because we have such a smooth, clear view of the world, it can be easy to overlook how much hard work our eyes and brain have to do to create this experience. Actually, our eyes are constantly moving in order to provide the brain with new information about the world around us. But why is this necessary? In this article, we will explore how and why our eyes move, and how the brain creates a visual experience from all the little snapshots of the world brought in through the eyes. 


\section{PERIPHERY}

The area of the retina that is outside of the fovea. There are fewer cones in this region compared with the fovea, so vision is blurrier here.

\section{FOVEA}

The small region in the center of the retina that supports very clear vision due to the large number of cones in this area.

\section{Figure 1}

Visual clarity is not the same in all parts of the eye. Hold the page at a normal reading distance. When you look at the purple circle directly, you can easily read the numbers and letters that surround it. When you look at the blue square, you can still see the purple circle in the corner of your eye, but you can no longer read the numbers and letters. When you look at something out of the corner of your eye, you are using your periphery. Your vision is best when you look directly at an object; this is because your fovea, which is in the very center of the eye, allows you to see most clearly.

\section{WHY DO WE NEED TO MOVE OUR EYES?}

One surprising fact about human vision is that, although the world appears uniformly clear to us, the clarity of the visual information we gather is not the same in all the parts of the eye. You can observe this yourself. First, stare at the purple circle in Figure 1. It is easy to read both the letters and the numbers surrounding the circle without moving your eyes. Now stare at the blue square. You can see the purple circle in the corner of your vision, but you can probably no longer read the numbers and letters around it. The blurry parts of your vision, where you can only gather limited information, are called the periphery (per-IF-er-ee). The clearest spot at the very center of your visual field is called the fovea (FO-vee-uh). The fovea is located at the center of an important inner layer of the eyes called the retina. One reason that the retina is so important to vision is because it is made up of special cells called photoreceptors.

When light enters the eyes, it first passes through the cornea, which is the clear dome at the front of the eyes (see Figure 2). The light then enters the pupil-the dark opening in the center of the eye-and travels into the lens, a part of the eye that helps focus the light properly. Finally, light passes through the main part of the inner eye, which is called the vitreous chamber. This chamber is filled with a gel-like substance called vitreous humor. Light that passes through the vitreous chamber is focused on the retina as a clear image. The photoreceptors located on the retina turn the light into neural messages that the brain understands.

Photoreceptors come in two varieties. Rods are photoreceptors that are sensitive to low levels of light and allow us to see our surroundings even when the environment is relatively dark. Cones are photoreceptors that carry information about color and support very clear vision in brightly lit environments. The fovea is a small space on the center of the retina where there are many cones packed closely together. The areas further away from the fovea have fewer cones. The way that cones are arranged in the fovea explains why the center of our vision is the clearest. But there is a problem with this arrangement! Because the fovea is very small, it can only send the brain information about a limited area of the world. The problem is that our attention is often caught by something in our periphery, and the fovea cannot be focused on more than one area at a time.

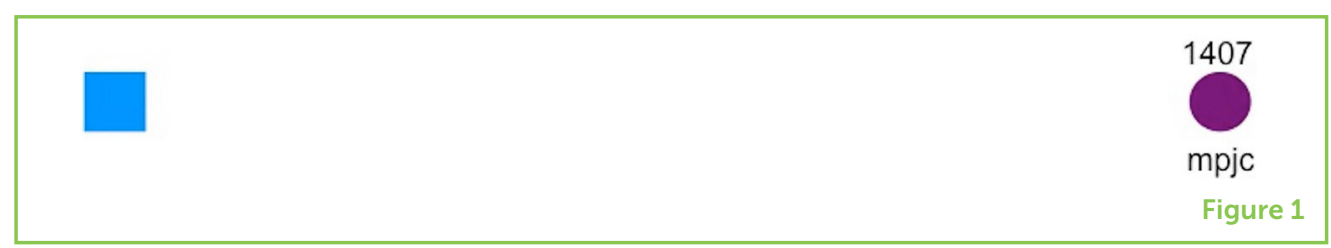


Figure 2

The parts of the eye are shown here, viewed from the side. Light first passes through the cornea-the clear dome at the front of your eye-and then goes through the pupil, a dark opening in the middle of the iris. The lens then focuses the light on the retina as it passes through the inner section of the eye called the vitreous chamber. The fovea is a small area at the center of the retina where there are many special cells called cones that help you see clearly.

\section{SACCADE}

A short, jerky movement made by both eyes that moves the gaze from one location to another.

\section{GAZE}

The combination of where the eyes are pointed and where the head is positioned in space.

\section{FIXATION}

The period of time between saccades when the eyes are at rest.

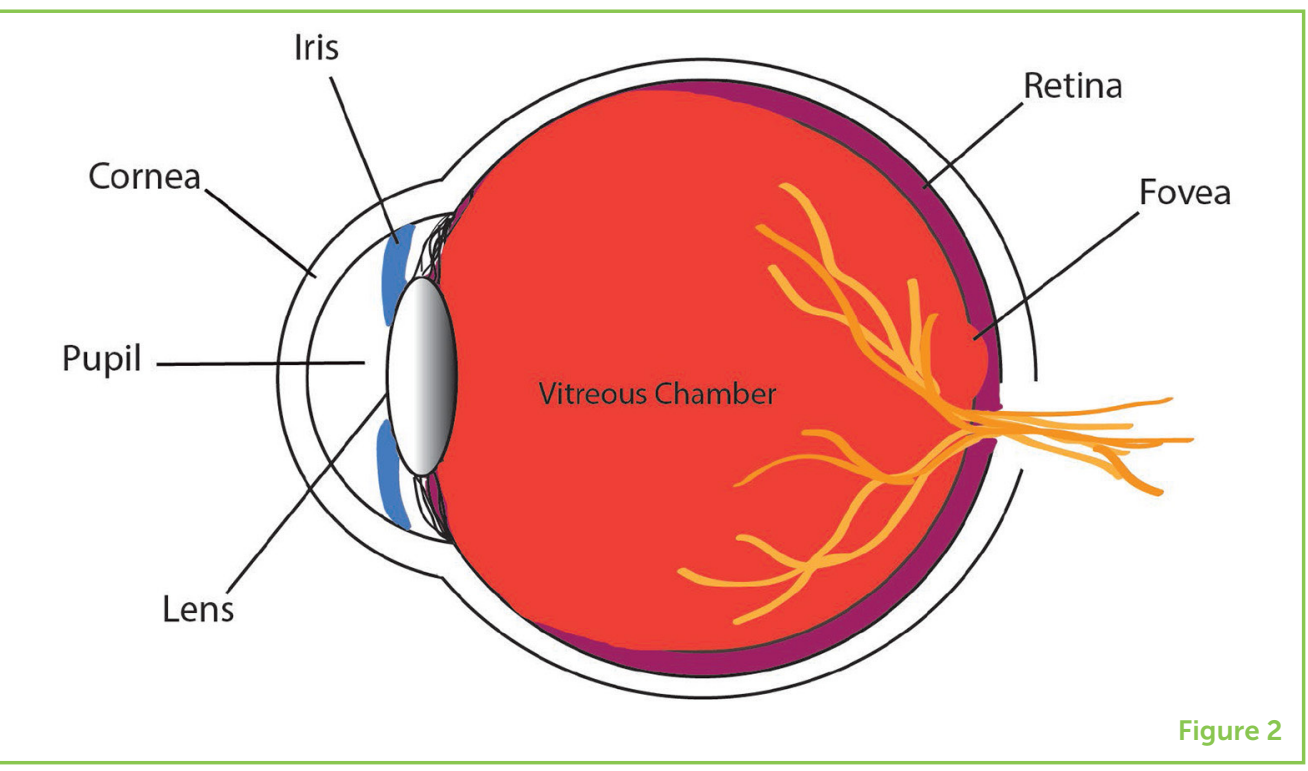

To compensate for the limited size of the fovea, we make many fast eye movements called saccades [1]. Saccades (suh-KODS) are short, jerky movements made by both eyes, which change the direction of the gaze from one location to another. Gaze refers to the combination of where your eyes are pointed and how your head is positioned. When you redirect your gaze, your fovea can focus on a new location and provide the brain with clear information about what is in the visual environment. For example, as you look at this page, the word you are currently reading (and a few around it) falls in the clear area provided by the fovea. In order to keep reading further along the article, your eyes need to make small saccades to bring new areas (words) into focus. Because you constantly need to move the location of your foveae to clearly see what you want to look at, your eyes have to make about three saccades per second. That means your eyes move more often than your heart beats!

Although you can make hundreds of thousands of saccades in a day, saccades are not the only kind of behavior the eyes perform. In between each saccade is a short period of rest, called a fixation. Fixations give your eyes a chance to focus on what you are looking at so that you can see clearly. During a fixation, the eyes send information to the brain about the fine details of the environment. Bit by bit, the brain can use this information to put together a full picture of what is in the world around you. To observe fixations and saccades yourself, you can try the following activity: grab a partner and stand in front of a mirror. First, look at your own reflection. When your eyes are at rest, you can see your own face. Now move your eyes around to different parts of your face. You cannot see your own eyes moving! However, if you look at your partner's reflection while he/she moves his/her eyes, you will be able to observe that your friend's eyes make many quick and jerky saccades. 
If your eyes constantly make fast movements, why do not you notice it happening? Should not the world look blurry during saccades? Even though your eyes are constantly making short, rapid movements, your brain constructs a smooth and stable representation of the environment. When your eyes are moving, you do not consciously recognize the visual information coming into the brain. This allows you to see the world clearly and stably, but it does not mean that no information is present. Even though this process is not well understood yet, scientists think that the visual information collected during saccades is present in the brain in a region called the cerebral cortex. The cerebral cortex may store information gathered during saccades, but it is not the only area of the brain involved in eye movements.

\section{NEURAL CONTROL OF SACCADES}

Saccades and fixations work together to supply the brain with the information it needs to create a mental picture of the world, but the brain is involved in controlling where the eyes will move next. The brain needs to tell the eyes how far and in which direction they should move. When something attracts your attention and you direct your foveae toward it, two brain structures are important in telling the eyes when and how to move: the superior colliculus and the frontal eye fields.

The region of the brain called the superior colliculus takes information from your eyes, ears, and other senses and uses that information to move your eyes toward things that catch your attention [2]. For example, if you are at school and hear the fire alarm go off in the corner of the room, your eyes will likely move toward the direction of that sound without you even thinking about it. The superior colliculus tells your eyes when and where to move, but it also helps control how you turn your head and shoulders. This is important because sometimes what you want to look at is out of the range of your eye movements. If a noise grabs your attention from behind you, for instance, you would need to move more of your body than just your eyes to be able to see what was causing the noise.

Another area of the brain, called the frontal eye fields, is important in helping you move your eyes toward an area that you deliberately choose to look at [3]. This part of the brain makes a plan for the eyes so that they know how and where to move, based on your goals and the visual features of objects in your environment. A visual feature is something that describes an object, such as shape, size, or color. You can think of the frontal eye fields as a mapmaker. This area of the brain maps out the visual features of your environment and how important or noticeable they are. If you are looking for a round clock, the frontal 
eye fields mark round shapes as important. It might also mark an area as important if it is very attention grabbing, such as a hot pink coffee mug on a bland, brown table. The area of the map that is deemed most important overall is where your eyes will move next. Now that you know a little bit about how eye movements work, let us take a look at how and why scientists study eye movements.

\section{HOW AND WHY SCIENTISTS STUDY EYE MOVEMENTS}

Eye tracking is a type of technology that allows a computer to calculate where your eyes are pointed. This lets scientists measure the saccades and fixations that your eyes make. There are several different types of eye trackers. Some eye trackers require you to sit in front of a computer screen with your head in a chin rest (see Figure 3A), while others can be attached to glasses frames or goggles so that you can walk around. Eye trackers typically use a small device that projects infrared light (a type of light that cannot be seen by humans) toward your eye. The infrared light causes a small reflection on the cornea. A camera positioned in front of the eye can detect this corneal reflection and use it to measure eye movements.

Eye movements are interesting to scientists because there is a strong relationship between what a person is looking at and what that person is thinking [4]. Generally, when you look at an object in your environment, your attention is also directed toward that object. For example, let us say that you look out the window because you hear a bird singing and you want to see what it looks like. Your attention is focused on the bird, and you are probably also thinking about how pleasant the bird's song is, or that its feathers are a nice shade of blue. Although gaze and attention are not always linked it this way, it is generally accepted that you pay attention to the objects you look at.

illuminator, sits

between the screen and the participant and records eye

movements. (B) An example of the path a participant's eyes might take around the screen during a visual search experiment that required the participant to look for a bell. Circles represent fixations and lines represent saccades. Knowing where a person looks during a visual search tells scientists where the person's attention is directed.

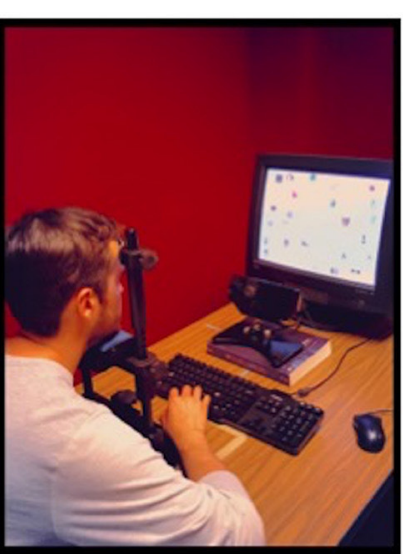

(a)

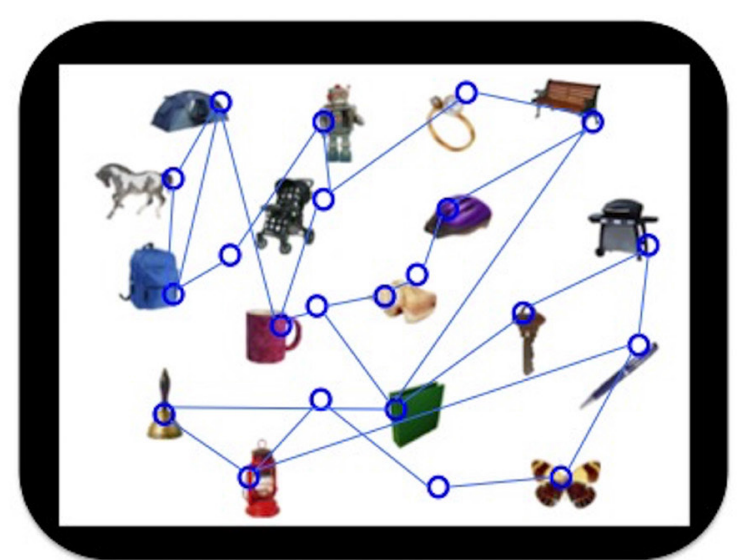

(b) 
Because of the close relationship between eye movements and attention, people who want to study how attention works often use eye tracking. For example, a storeowner who wants to know where to place products might use eye tracking to determine which areas people look at most often when shopping. Another use for eye tracking is to explore how people look for specific objects in their environment-this area of research is called visual search. In visual search experiments, participants are given a target (a specific picture or image) to look for among other distracting images or pictures. If you have ever done Where is Waldo, looked for a missing toy in your room, or helped your parents find their keys, you have performed visual search. Using eye trackers to study visual search allows scientists to investigate how people choose what to pay attention to when they look for a target (see Figure 3B).

The study of eye movements has taught scientists not only about how the eyes and brain work together to see the world, but has also brought us closer to understanding how mental activities like attention operate. The eyes (and the movements they make) help people gather the visual information they need to make sense of the environment. Every time we move our eyes, we supply our brains with important new information about things in the world; in short, we get a new "snapshot" about what is going on in each region of space around us. Information like the shapes, colors, textures, and edges of objects. The brain uses this information to help us understand the world around us. For instance, that the fluffy orange texture in front of us belongs to a cat that we need to avoid stepping on, and the sharp edge we see is a table corner we need to avoid bumping into. By studying eye movements, we can see that even the smallest and simplest of movements can have a big impact on our lives.

\section{REFERENCES}

1. Yarbus, A. L. 1967. "Saccadic eye movements," Eye Movements and Vision (Boston, MA: Springer). p. 129-46.

2. Klier, E. M., Wang, H., and Crawford, J. D. 2001. The superior colliculus encodes gaze commands in retinal coordinates. Nat. Neurosci. 4:627. doi: 10.1038/88450

3. Purves, D., Augustine, G. J., Fitzpatrick, D., Katz, L. C., LaMantia, A. S., McNamara, J. O., et al. 2001. Neuroscience. 2nd Edn. Neural Control of Saccadic Eye Movements. Sunderland, MA: Sinauer Associates. Available online at: https:// www.ncbi.nlm.nih.gov/books/NBK10992/

4. Just, M. A., and Carpenter, P. A. 1980. A theory of reading: from eye fixations to comprehension. Psychol. Rev. 87:329. 
SUBMITTED: 12 June 2018; ACCEPTED: 05 December 2018; PUBLISHED ONLINE: 18 December 2018.

EDITED BY: James A. Mazer, Montana State University, United States

CITATION: Madrid J and Hout MC (2018) Eye Spy: Why we Need to Move our Eyes to Gather Information About the World. Front. Young Minds 6:71. doi: 10.3389/ frym.2018.00071

CONFLICT OF INTEREST STATEMENT: The authors declare that the research was conducted in the absence of any commercial or financial relationships that could be construed as a potential conflict of interest.

COPYRIGHT () 2018 Madrid and Hout. This is an open-access article distributed under the terms of the Creative Commons Attribution License (CC BY). The use, distribution or reproduction in other forums is permitted, provided the original author(s) and the copyright owner(s) are credited and that the original publication in this journal is cited, in accordance with accepted academic practice. No use, distribution or reproduction is permitted which does not comply with these terms.

\section{YOUNG REVIEWER}

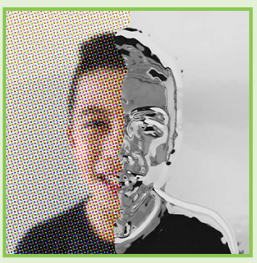

\section{GONI, AGE: 10}

I like reading, video games, and playing sports. I play soccer and baseball. My favorite food is pizza. I recently moved to Israel and we are staying here for 1 year.

\section{AUTHORS}
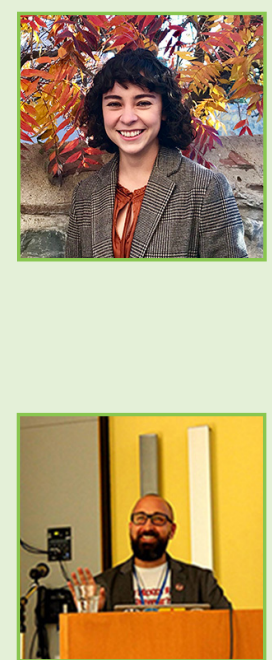

\section{JESSICA MADRID}

I am a Ph.D. student at New Mexico State University, where I study how the mind performs everyday tasks like remembering and looking for objects. My favorite thing about studying psychology is learning about how mental tasks that seem simple are actually very complex. My research focuses on how visual search and memory work together to allow people to search for many things at the same time. When I am not working, I like to read, cook new recipes, and play with my cat named Mouse.

\section{MICHAEL C. HOUT}

I am an Associate Professor in the Psychology Department at New Mexico State University, and an Associate Editor at the journal Attention, Perception, \& Psychophysics. My research examines many different things, but I primarily study visual search (how people find things) and eye movements (where and why we move our eyes). In my limited spare time, I like to play with my dogs, go on motorcycle rides, hike, travel, and play hockey. ${ }^{*}$ mhout@nmsu.edu 